\title{
CAPACITY OF FRACTOGRAPHIC ANALYSIS FOR LOAD-TIME HISTORY RECONSTRUCTION AND FATIGUE CRACK GROWTH RATE ESTIMATION FOR THE 2024-T3 ALUMINIUM ALLOY
}

\author{
Zdzisław Bogdanowicz \\ Dorota Kocańda \\ Janusz Torzewski \\ Military University of Technology, \\ Warsaw, Poland
}

\begin{abstract}
The subject of the paper is the considerations for the feasibility of load time history reconstruction on the basis of microfracture analysis for a failed component made of 2024-T3 aluminium alloy that operates under variable amplitude loading. For this goal three different variable amplitude load sequences with single and multiple overloads and underloads were applied to investigate crack growth rate and to examine the images of fatigue striations on the fracture surface of a component. These loads are employed when simulating the fatigue crack behaviour in aeronautical alloys. Microfracture analysis was also used either for learning the interaction of variable amplitude loading for crack growth rate in 2024-T3 alloy or for establishing the relation between surface crack and crack depth growth.
\end{abstract}

\section{INTRODUCTION}

Feasibility of reconstruction of fatigue crack growth in a component on the base of fractographic analysis is well known and practically used since many years. For this goal characteristic features of fracture surface of the component, namely macroscopic growth lines as well as the fatigue striations in relation to the applied load are analysed. However, in many cases either of loads or the tested materials the fatigue striations may be invisible on the fracture surface. Furthermore, the relation one cycle-one striation may be satisfied only in a middle part of the crack growth curve. Many researches developed for this purpose indicate that the growth rate estimated from the striations spacing is higher in the commence stage of crack growth and lower in the final stage of crack growth than the rate when determining by another methods [1]. Of course, it is not the rule. For instance, mutual correspondence between the crack growth rates was appeared for 2024-T3 aluminium alloy at the constant amplitude loading in whole range of crack growth [2]. In the present work some successive researches developed in the scope of load-time history reconstruction for aluminium alloys by means of fractographic analysis will be mentioned.

In [3] was pointed out that the micrographs taken from the fracture surfaces of 2024-T3 test samples conducted under simulated spectrum load have correctly imaged the load history. Furthermore, the features of fracture surface were similar to these ones which were related to a real structure under service loading. The bands lain between visible fatigue striations were corresponded to 5000 flights. Spectrum loading has been accurately marked on the fracture surface by the systems of fatigue striations in aerospace aluminium alloy AA7010 [4]. Experimentally determined crack growth rate for A2017-T3 aluminium alloy under three-step varying load was compared with the rate estimated from the striations spacing [5]. Pretty good agreement between these rates has been achieved for two load sequences. In case of third load program the results were completely divergent. Microfracture analysis was employed in order to investigate the 
influence of applied load sequences on crack growth rates for 2024 alloy after different surface treatments [6]. The results of this experiment have permitted unique discrimination of the interaction effects between applied load and the relative changes in formation of fatigue striations. The effect of hydrogen environment embrittlement on fatigue crack growth behaviour in six aerospace aluminium alloys, among them also in 2024-T3 alloy, was the subject of [7]. Extensive investigations in this field were conducted in the conditions of time-dependent hydrogen exposure as well as time-dependent cyclic deformation in gaseous, aqueous environments and in ultra-high vacuum. SEM micrograph derived from a transition zone has revealed in 2024-T3 alloy a quasicleavage mechanism of cracking in vacuum and afterwards the occurrence of fatigue striations when the cracking process was developed on in moist air. Fatigue striations were invisible in 7075-T3 alloy plates with semi-elliptical notches under constant amplitude tension [8]. However, the presence of fatigue striations was confirmed after inserting the overloads in the basic load spectrum.

The importance of fractography supporting the analysis of failure case of real structures has been pointed out by J. Schijve either in the book [9] or at the ECF-14 conference in Cracow [10]. Special needs with respect to fatigue damage of aircraft components persist also the researches into fatigue crack propagation in aerospace aluminium alloys under different types of load-time histories. These reasons require special skills for finding the correlation between the images of fracture surface and accumulated fatigue damage due to applied load. The relation one cycle-one striation has been examined in [9] in order to determine the rates of crack growth for different types of simulated service loading and then shown on the diagrams of growth rates versus number of cycles. However, it should be mentioned that the references devoted to this problem provide both positive and negative opinions relating to the fractography ability when reconstructing the load-time history of a failed component. A surprising results were obtained in [11] when investigating in situ small crack behaviour in 2024-T351 polycrystalline alloy under tension and under bending. The analysis of fracture surface proved a plastic mechanism of cracking. However, fatigue striations were not evident on the surface.

Load interaction effects on fatigue crack growth response when imposing a single or multiple overloads are widely reported in the references. For load histories containing overloads the evidence of fatigue striations on fracture surface depends on particular combination of load parameters and material. When relating the crack growth to the load parameters one needs to take into account the number and the frequency of overloads imposed during basic loading (BL) as well as the ratio of the overload stress OLR defined below. However, it can happen that the multiple overloads which intersperse the baseline cycles do not mark the striations on fracture surface. This case is often observed in aluminium alloys and is reported in the studies mentioned below. Negligible effect of overloads on the crack growth rate appeared in aluminium alloys such as 2024-T3 [12], 7075 and 8090 [13] under aircraft service spectrum as well as in successive another seven aerospace aluminium alloys [14]. This fact found confirmation on the plots of crack growth rate also for 2524-T3 Alclad aluminium sheets and in titanium alloys [15] under the Embraer simulated service utilisation. In contrary, stronger interaction effects on crack growth behaviour appeared in 2024-T3 when a single overload was applied and afterwards multiple repeated until failure [12]. The mentioned results found confirmation also in our research developed for 2024-T3 aluminium alloy.

Therefore, there a considerable interest is to evaluate the capacity of the models for fatigue crack growth prediction. For this goal a research program into fatigue crack growth behaviour has been developed for thin 2024 sheets after two different heat treatments T3 and T2 under variable amplitude sequences typical to helicopter utilisation to support analytical and numerical modelling of crack growth in lower wing skin [16]. It was stated that 2024-T2 specimens exhibited slightly longer crack propagation lives with respect to 2024-T3 Alclad specimens. Accuracy and the reliability of the prediction models commonly used by FASTRAN, NASGRO, CORPUS and 
AFGROW have been tested to evaluate the plots of crack length versus number of cycles as well as the distribution of the ratio of the number of cycles measured in the experimental test over the calculated ones, for a given crack growth intervals. The results of comparisons showed big discrepancies between these plots. The retardation and acceleration effects due to imposed overloads have been clearly marked on the experimental plots. The trends in crack growth behaviour have been illustrated only by three predicted plots. The worst results were derived by AFGROW. Crack growth analysis for 7075-T6 aluminium alloy under service loading with the help of identical numerical programs as mentioned in [16] was the subject of the work [17]. A wide review of fatigue crack growth behaviour for the metallic materials, among them also for aluminium alloys, under variable amplitude both simple and complex load sequences as well as the presentation of fatigue crack growth prediction models contains the monograph [18].

Fractographic analysis is practically used also in order to analyse the failure case of real structures and to reconstruct the exploitative loading of failed components. The importance of fractography supporting those analyses was pointed out in the books published either by V.C Ivanova et al. [19] or by J. Schijve [10]. However, in many cases either of the loads or the tested materials, the fatigue striations may be invisible on the fracture surface and the load reconstruction impossible. This case is often observed in aluminium alloys. On the other side special needs concerning fatigue damage of aircraft components inspire the researchers to investigate fatigue crack propagation in aerospace aluminium alloys under different types of loading to learn the striation systems formed on the fracture surface. For load histories containing overloads, the evidence of fatigue striations on fracture surface depends on particular combination of load parameters and material. It can happen that the multiple overloads which intersperse the baseline cycles do not mark the striations on the fracture surface. The mentioned results were also confirmed in our research developed for 2024-T3 aluminium alloy [20]. Fractography was also used to analyse fatigue crack initiation and growth in aeronautical aluminium alloy rivet-joints $[22,24]$ as well as to estimate the influence of amplitude and load rate on energy dissipation for aluminium alloy subjected to cyclic torsion [23].

The present work derives the results of fatigue crack growth response in 2024-T3 Alclad aluminium alloy to the application of three variable amplitude (VA) load sequences which are employed when simulating the fatigue behaviour of aeronautical alloys. The problem of reconstruction of the load-time history of the component as well as the fatigue crack growth rate on the basis of microfracture analysis is also considered here.

\section{MATERIAL. EXPERIMENTAL PROCEDURE}

The material used for testing was 2024-T3 Alclad aluminium alloy sheet of $3 \mathrm{~mm}$ thickness. Clad layer thickness was $0.120 \mathrm{~mm}$. The central crack tension specimens (CCT) had the size of $400 \mathrm{~mm}$ length and $100 \mathrm{~mm}$ width (Fig.1). In order to facilitate comparison of fatigue properties with respect to sheet rolling direction, the specimens were cut in directions parallel (LT) and transverse (TL) due to rolling. The mechanical properties were in the following ranges: ultimate tensile stress 447-466 MPa, yield stress 303-335 MPa, elongation 21-24\%. The highest values of these properties were found for LT specimens. The average grain diameters in the clad layer were 85-89 $\mu \mathrm{m}$, and in the matrix material, respectively, $29-35 \mu \mathrm{m}$ in the LT direction and 18-25 $\mu \mathrm{m}$ in $\mathrm{TL}$ one. In those specimens tested under constant amplitude (CA) cyclic tension $(\mathrm{R}=0.1)$ the crack growth rates were found to be independent on the cutting direction.

For crack propagation studies, the specimens were provided with a central notch consisting of a through-thickness hole of $5 \mathrm{~mm}$ diameter, through-thickness saw cut of 2,5 mm length and precracking of $2.5 \mathrm{~mm}$ length on each side of the hole. The initial crack length was equalled to $2 a=$ $15 \mathrm{~mm}$, counting the length from tip to tip of pre-cracking. All fatigue tests were carried out under load control cyclic tension with a frequency of $2 \mathrm{~Hz}$. 
To check the ability of microfracture analysis for the load-time history reconstruction for 2024T3 aluminium alloy three variable amplitude (VA) load programs were applied (Figs. 2, 3, 4) that differ from the level of load sequence complexity. They are employed for crack propagation tests under flight simulation loads of lower skin of aircraft wing.
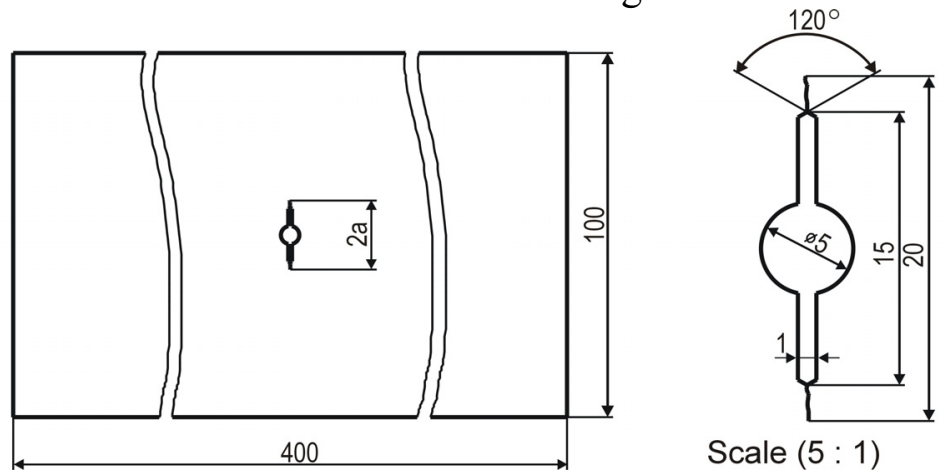

Fig. 1. Geometry of specimen (dimensions in mm)

First program named here as OVL was proposed by J. Schijve. It contains a load sequence of 211 cycles with few overloads, as shown in Fig. 2.

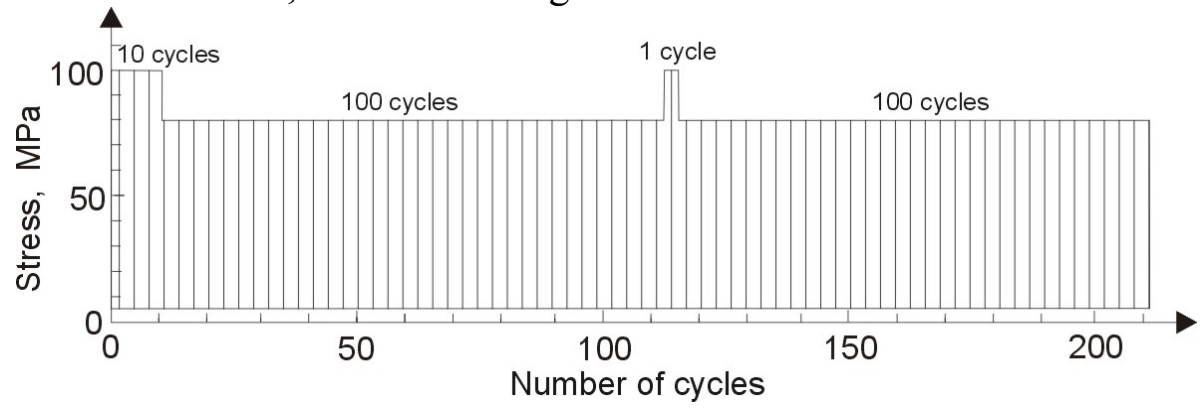

Fig.2. Load sequence with overloads (OVL-program)

The basic constant-amplitude load (CA) is interspersed by 10 uploads, and then by a single similar upload followed by 100 basic cycles. Successive 10 overloads are also preceded by 100 basic cycles. Maximum stress at the overload is $\mathrm{Smax}=100 \mathrm{MPa}$, the overload rate OLR=1.266. Overload rate OLR is defined as $\mathrm{OLR}=\left(\mathrm{K}_{\mathrm{OL}}-\mathrm{K}_{\min , \mathrm{BL}}\right) /\left(\Delta \mathrm{K}_{\mathrm{BL}}\right)$ where $\mathrm{K}_{\mathrm{OL}}, \mathrm{K}_{\min , \mathrm{BL}}$ and $\Delta \mathrm{K}_{\mathrm{BL}}$ mean stress intensity factors at the overload and at the minimum stress of basic cycles and the range of stress intensity factor calculated for the baseline, respectively.

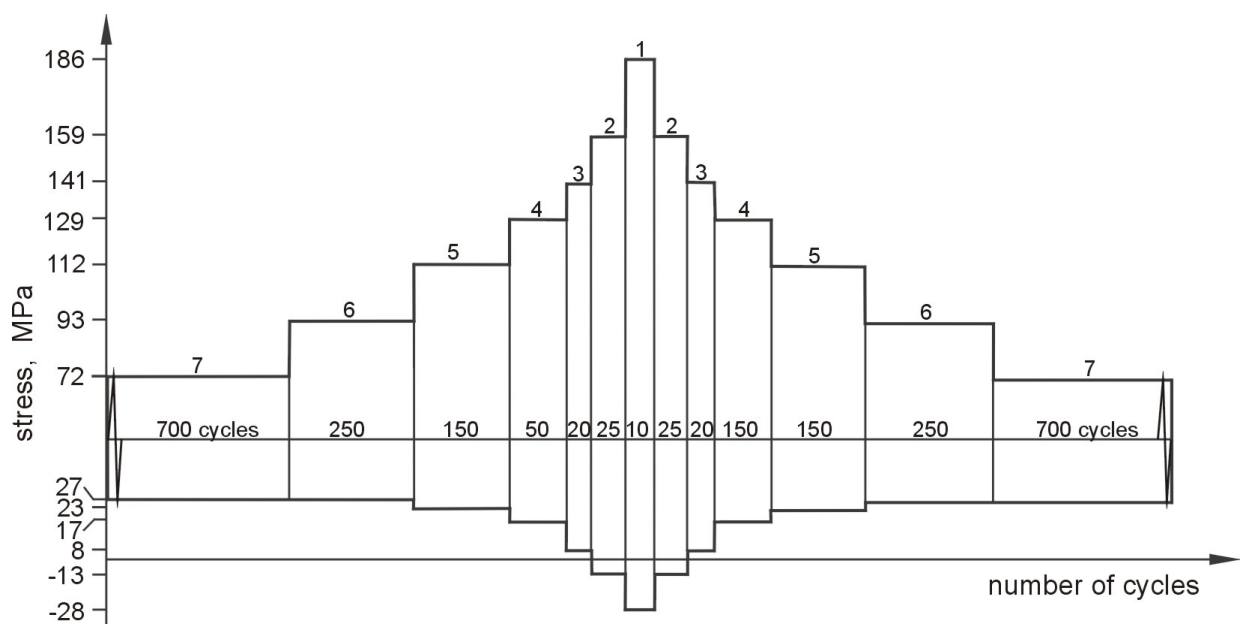

Fig. 3. Scheme of LHL-100 block program 
Second load program called as LHL-100 (Fig. 3) has a flight schedule of 100 flights with the load cycles ordered in 13 blocks. Each block has the same maximum and minimum load, but the range of the stress amplitude and the number of cycles depend on the stress levels numbered from 1 to 7 . One LHL-100 program has 2400 total number of cycles.

Third VA load program called as FBF (flight-by-flight), with the scheme shown in Fig. 4, consists of two blocks of cycles: Flight A and Flight B. Within one FAF load sequence the block Flight A is nine times repeated whereas block Flight B only one time. One whole load sequence counts 240 cycles. Either Flight A or Flight B are of the low-high-low shape with various magnitude spike overloads-underloads. Ten FBF sequences equilibrate one LHL-100 block program.

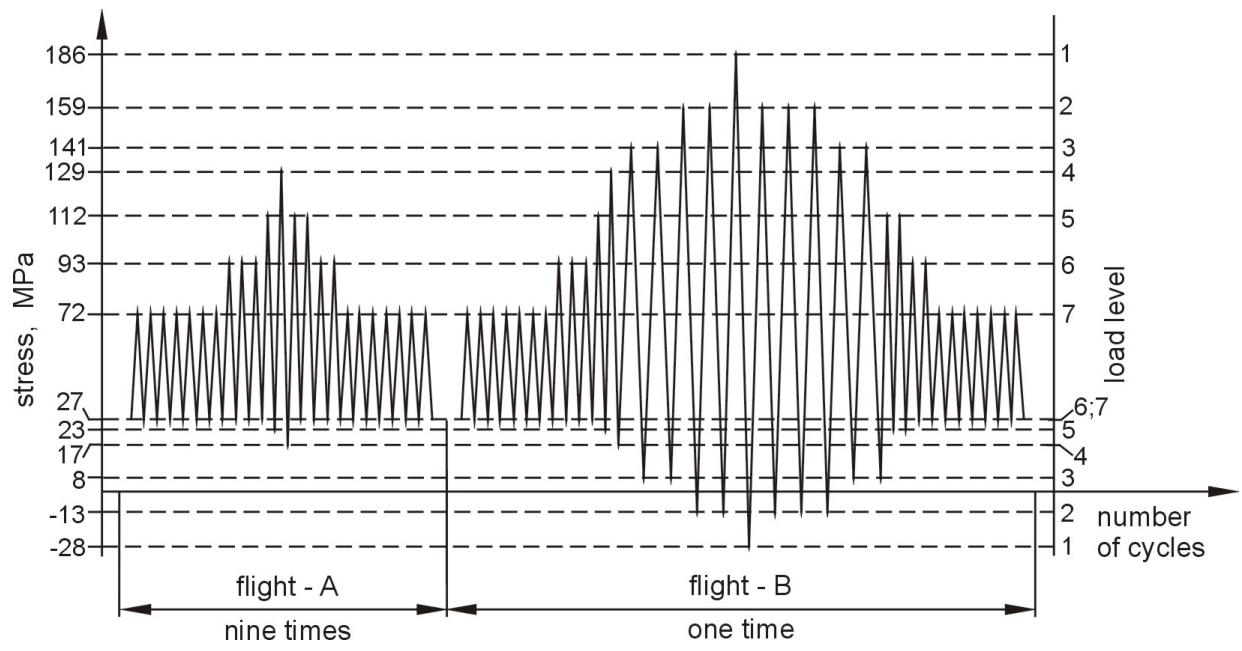

Fig. 4. Scheme of FBF cycles sequence

All load programs were repeated until the specimen failure. The X-ray diffraction method revealed the compressive residual stresses of value $40 \mathrm{MPa}$ in the Alclad layer either in precracked or without pre-cracked LT and TL specimens. The crack length was monitored visually using a magnifying glass. For visual recording of the crack tip positions a line scale was inscribed on the specimen surfaces along the crack path. The accuracy of crack length readings was $0.2 \mathrm{~mm}$. Additionally, the region of the crack tip was recorded by the video camera. The load sequence effect on crack growth rate behaviour was analysed by means of the transmission electron microscope (TEM). Prior to the TEM observations the plastic replicas taken from the fracture surfaces were shadowed by platinum.

\section{RESULTS AND DISCUSSION}

\section{Fatigue crack growth under variable amplitude loading}

It should be emphasized that the considerations for fatigue crack growth behaviour under variable amplitude loading (VA) refer only to long crack. The discussion of the obtained results will be provided separately for each load test.

\subsection{Test results for OVL program}

Fatigue crack growth response for 2024-T3 aluminium alloy under OVL program (Fig. 2) is analysed on the basis of Fig. 5 and Fig. 7 as well as the image in Fig. 6 of the fracture surface with fatigue striations relevant to this load program. In Fig. 5 experimental data set of the surface crack growth rates referred to OVL program was compared with the data associated with surface crack growth rate under CA loading. As it was expected, the multiple overloads imposed in the stress amplitude baseline caused a significant reduction in growth rates. However, the retardation and acceleration effects associated with a particular block of overloads are not clearly visible on the experimental plots in Fig. 5. Probably, it resulted from the methodology used when measuring crack length on the specimen surface. 

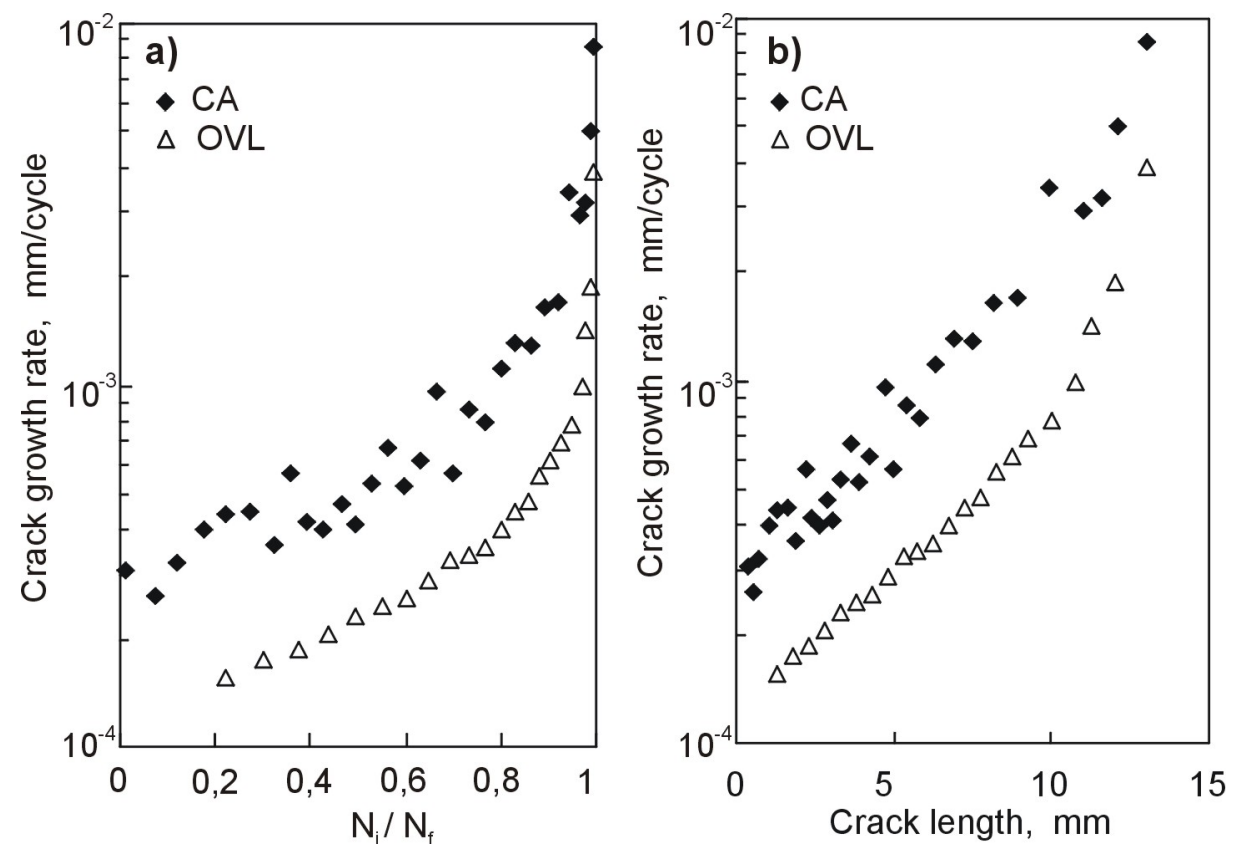

Fig. 5. Experimental curves of fatigue crack growth rates versus crack length (a) and cycle ratio $N_{i} / N_{f}$ (b) under constant amplitude (CA) and programming loading $(\mathrm{OVL})$, respectively

On the contrary, the effects of the overloads on crack growth rate can be considered when taking into account the TEM micrograph that originates from the spots at different distances from the notch root. Exemplary TEM micrograph with the striations seen in Fig. 6 corresponds to a half of the load sequence. On the image, from left to the right side, one can easily identify the band with 10 ,thicker" striations attributed to 10 applied overloads, then the band with 100 ,tiny” striations corresponded to 100 basic cycles and a single "thicker" striation induced by one overload. Ten overloads give rise to severe retardation effect which appears immediate after applying the overloads. When approaching the single thicker striation then the spacing between them gradually increases because of an acceleration in growth rate.

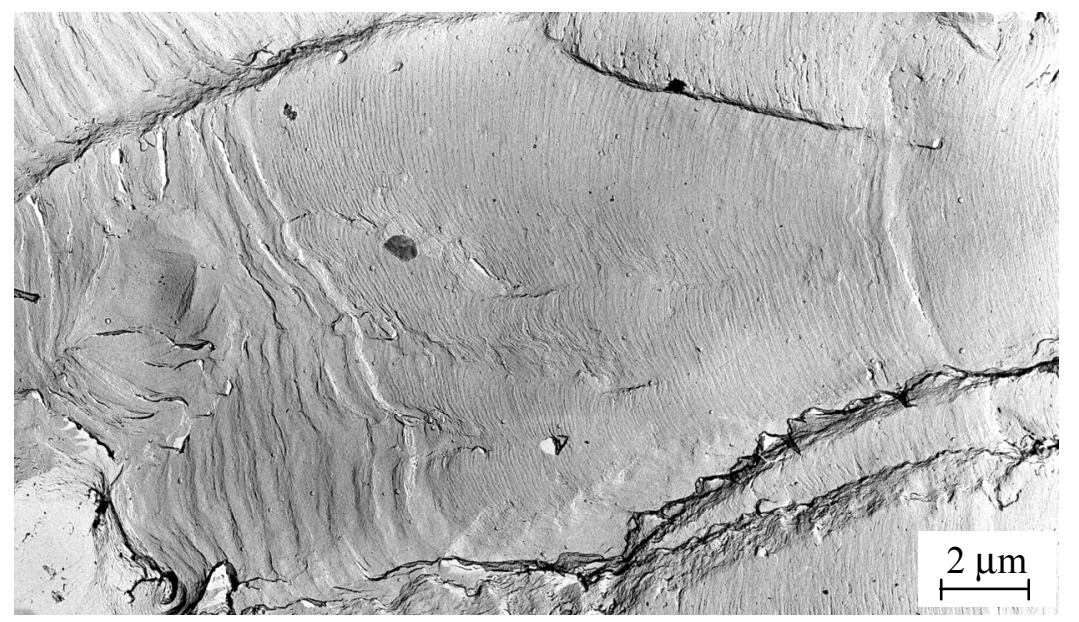

Fig. 6. TEM micrograph illustrates the system of fatigue striations formed under OVL load test

The TEM micrograph allow us accurately reconstruct the history of loading as well as the changes of crack growth rates in 2024-T3 alloy under the OVL loading. The courses of local 
growth rates affected by particular whole cycle sequences and estimated on the basis of striations spacing against crack length are shown in Fig 7.

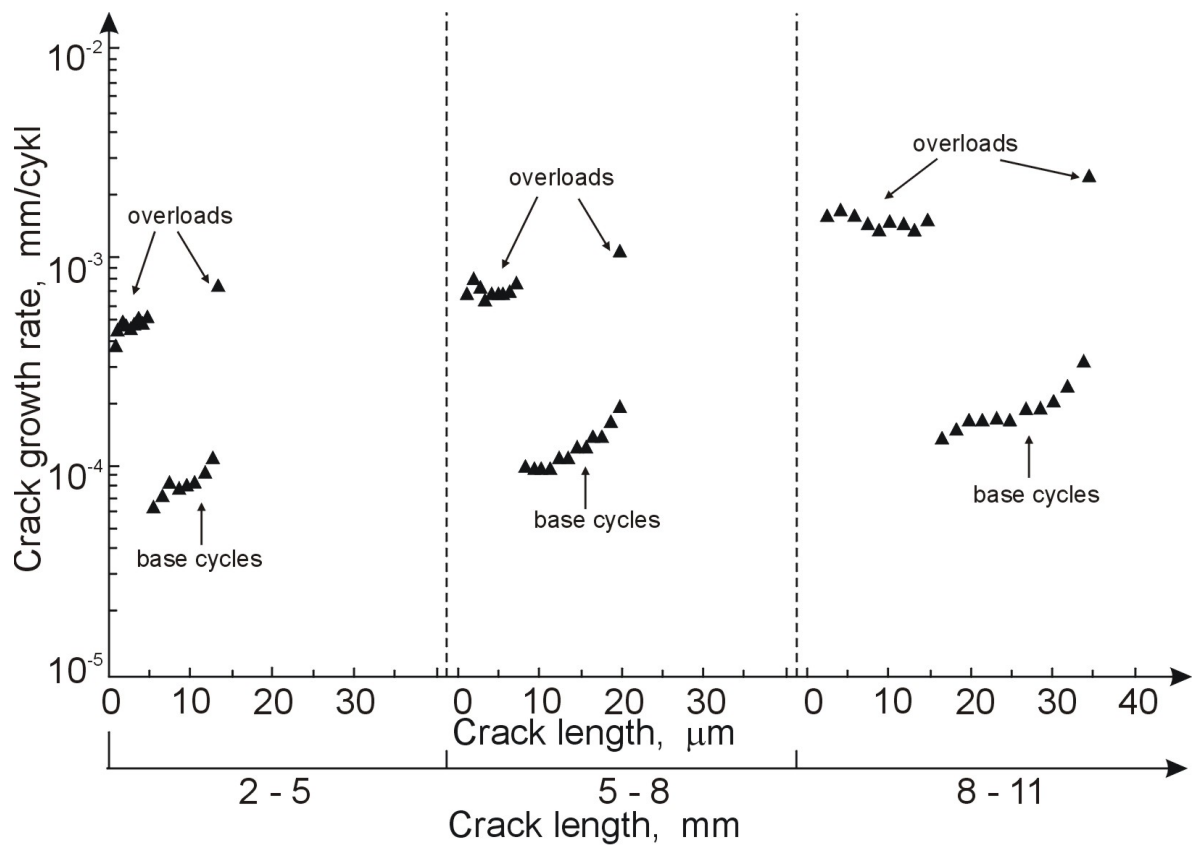

Fig. 7. Courses of local crack growth rate against crack length; see text for explanation

On double horizontal axis are marked the intervals of the crack length in milimeters, counting from the pre-cracking, whereas on the lower axis the crack length increment in micrometers is calculated from the striations spacing. As it is seen on the diagram ten overloads produce initially a high growth rate. However, under successively following overloads the rate shows a decreasing tendency and eventually a rapid drop almost of two orders of magnitude. Afterwards, the rate gradually increases in the period corresponded to 100 baseline cycles showing also certain periods of constant rates. Imposition of a single overload in the basic cycles results either in an immediate short jump of growth rate or its rapid drop of one order of magnitude. The load interaction leads to a delayed retardation of crack growth and then to its gradual rising in the period associated with the application of subsequent 100 basic cycles. The crack retardation is associated with a plastic zone ahead of a crack tip, produced by the overloads. The compressive stresses acted in this zone temporarily close the tip of the crack. As it is seen in the diagram multiple overloads give rise to a more severe crack growth rate retardation than a single overload. One can note a significant rise of crack growth rate with increasing number of load sequences passed in the test.

\subsection{Test results for LHL-100 block program loading}

Results of fatigue crack growth rates relevant to the LHL-100 loading as well as to the CA test against measured surface crack length are shown in Fig. 8 for specimens taken in directions parallel - LT (Fig. 8a) and transverse - TL (Fig. 8b) due to rolling. The data marked by open (white) symbols refer to the surface crack length recorded visually (OPT). The data marked by filled-in black symbols represent fractographic measure (spacing between fatigue striations on the fracture surface) of crack depth by using scanning electron microscope (SEM). These date were compared with the data associated with surface crack growth rate under CA loading. 

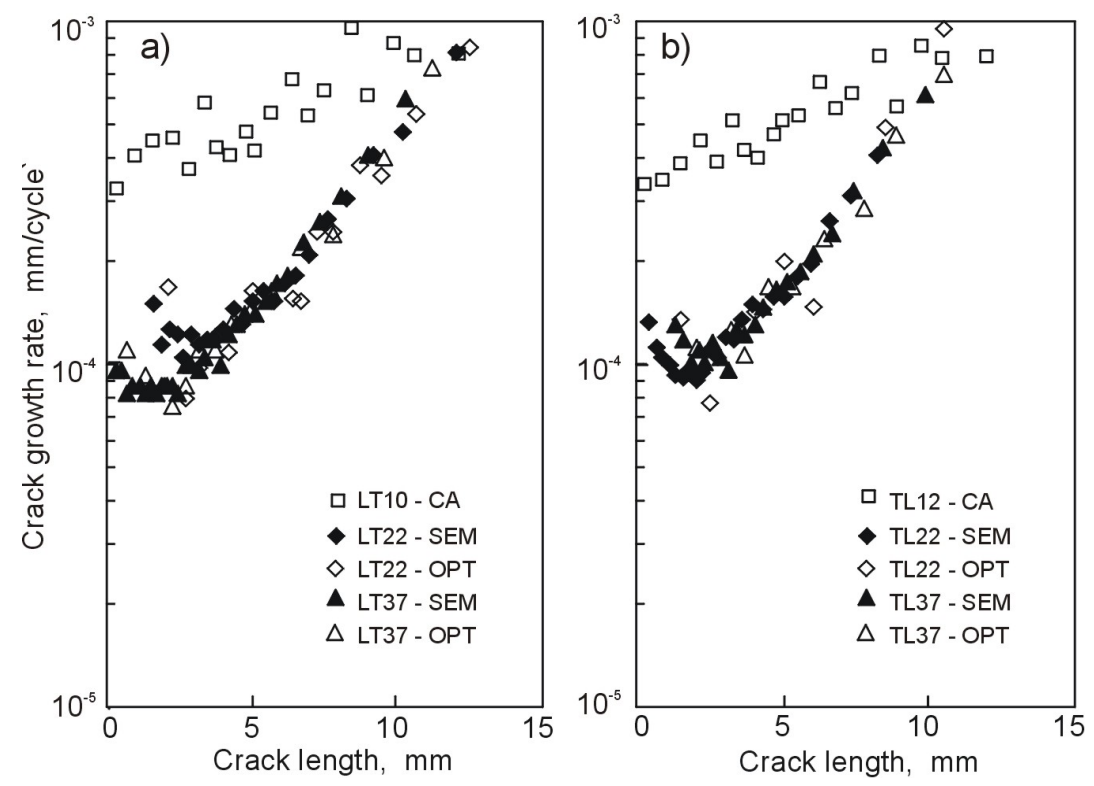

Fig. 8. Comparison of crack growth rates for LHL-100 block program and CA loading against crack length for specimens taken in directions parallel (a) and transverse (b) due to rolling

Discrepancies between these two VA data sets are small similarly to those in CA tests. Similar trend was observed for TL specimens, though crack growth rate was slightly higher in the TL than in LT specimens. All VA results fall significantly below the CA test data (Fig. $8 \mathrm{a}$ and $8 \mathrm{~b}$ ) because LHL block program strongly reduces the growth rate in the most part of the specimens' lifetime. In the final part of the fatigue life the VA growth rate reaches the CA rate.

The effect of load interaction on crack growth rates attributed to the particular load blocks is not clearly visible on the experimental plots. To learn better this effect the TEM or SEM micrographs should be analysed. Exemplary TEM micrographs in Fig. 9 shows a system of fatigue striations which corresponds to descending and then to ascending parts of one full block program observed on the fracture surface in the distance from 2 to $8 \mathrm{~mm}$ from the notch root.

The images illustrate particular ranges of the lengths of cracks measured from the fatigue precrack front, which are respectively equal to 2-5 mm (Fig. 9a), 5-8 mm (Fig. 9b) and 8-11 mm (Figure 3.10). In the specimens loaded according to the LHL program, they are the repeating patterns of fatigue striations which are observable under the TEM up to the length of $12 \mathrm{~mm}$ from the mechanical notch. The systems of fatigue striations can be observed in the increasing part of the spectrum at levels 3-2-1 and in the decreasing part of the spectrum at levels 1-2-3. At the load levels 7-6-5-4 and 4-5-6-7, there are merely trace quantities of striations, which indicates the arrest of the crack growth or its propagation at a vary low rate.

The nature of the transition of the crack path from the increasing to the decreasing part of the spectrum can be observed in the images. The transition may manifest itself in a step and a narrow strip (see Fig. 9a and 10) or in very narrow bands (see Fig. 9b). The transitions may be observed in the central parts of the images. The transitions manifest themselves in steps and smooth bands with either no fatigue striations or merely the traces of striations. The dimensions of the peculiar crack surface segments are approximately $3 \mu \mathrm{m}$ (Fig. 9a and 9b) and about 1,5 $\mu \mathrm{m}$ (Fig. 10). In accordance with the number of cycles in particular load levels (see Fig. 3), the analyzed bands correspond to 2300 load cycles (load levels 4-5-6-7), while the striated segments correspond to 100 load cycles (load levels 1-2-3). The images in Figures 9 and 10 indicate the crack tip closure or the propagation of the crack at a very low rate, which constitutes a proof of the crack growth retardation in a microscopic scale. The increasing striation spacing, especially in the image in Figure 10, indicates an increase in the crack growth rate. The gradual increase or decrease in the striation spacing in particular series may be ascribed to specific levels in the load spectrum. 


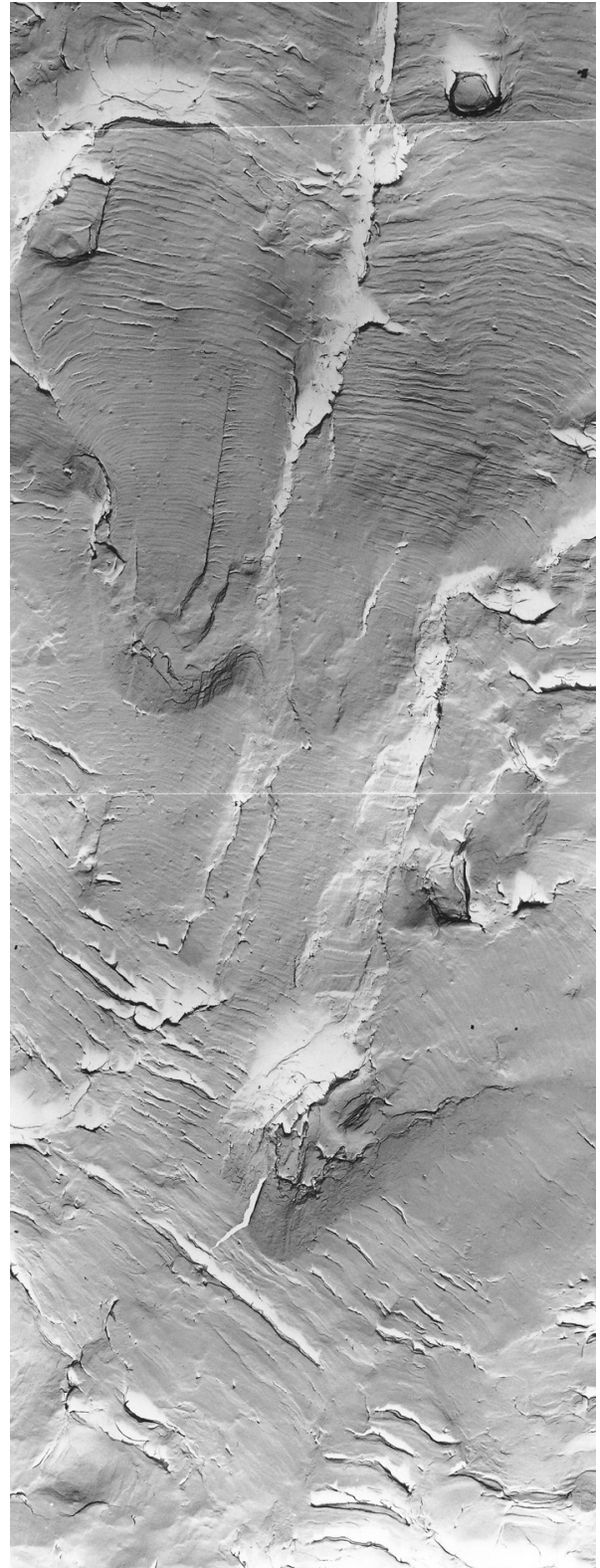

a)

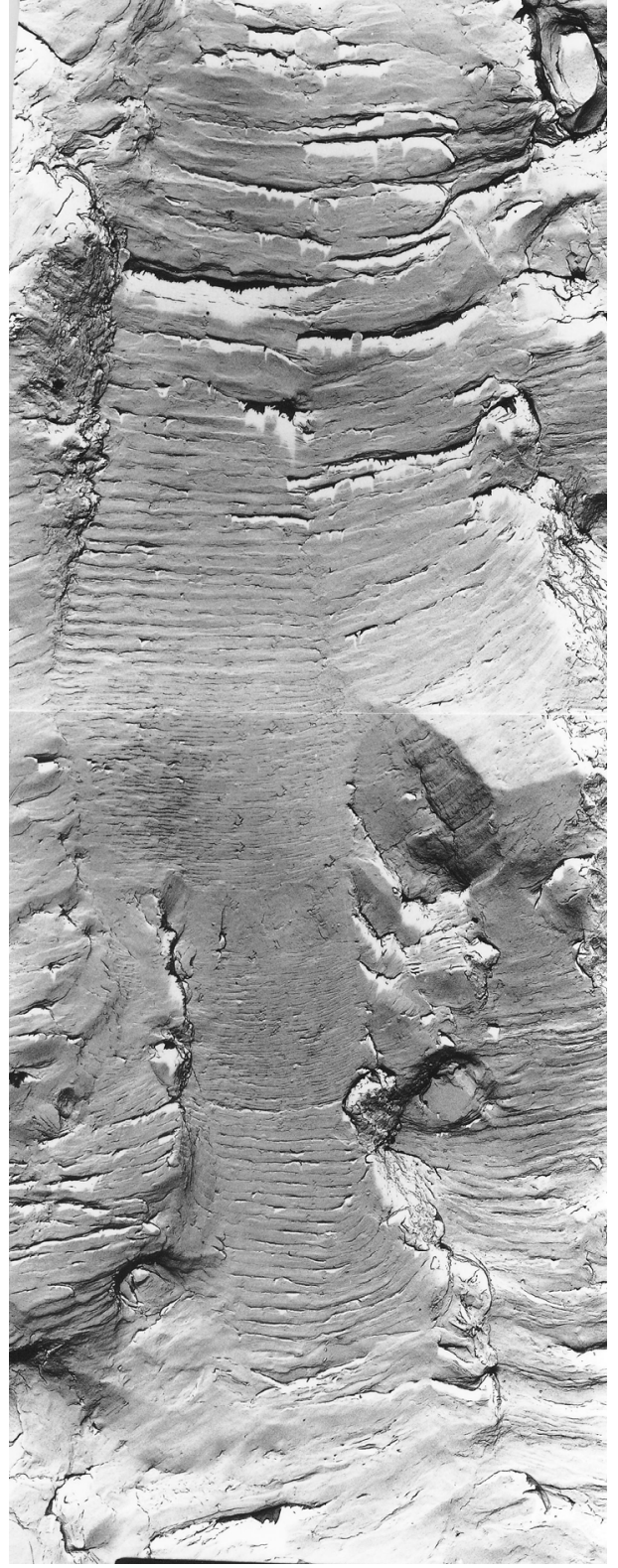

b)

Fig. 9. The patterns of fatigue striations on the fracture surfaces of 2024-T3 alloy L-T specimens observed under the TEM within the parts of stress spectra in the ranges of the lengths of 2-5 $\mathrm{mm}$ (a) and 5-8 $\mathrm{mm}$ (b) from the precrack front (explained below)

Local changes in the crack growth direction, as in Fig. 9a and to some extent in Fig. 10, were caused by second phase inclusions or cavities left after them, which can be observed in the right part of the image in Fig. 9a. Whereas quite a large pyramid-shaped inclusion, which can be observed in the central right part of the image in Fig. 9b, did not change the cracking direction. An identical inclusion in the left part of the image in Fig. 10 affected the direction of cracking to a small extent, however, it interrupted the continuity of wide striations.

The images of fracture surfaces obtained by means of the SEM are less clear and more difficult to interpret. Exemplary images are presented in Fig. 11. They illustrate the fracture surfaces of LT specimens. Extensive and somewhat jagged fracture surfaces as well as second intermetallic phase inclusions and cavities left after the removal of the inclusions disturb the uniformity of cracking and deteriorate the legibility of the images. The image in Fig. 11a was taken from a distance of $\mathrm{a}=1.5 \mathrm{~mm}$ from the fatigue precrack while the image in Fig. $11 \mathrm{~b}$ were taken from the distances of $\mathrm{a}=3.5 \mathrm{~mm}$. The image in Fig. 11a shows two series of clearly evident thick and thin striations, 
which correspond to the number of overload cycles in stress blocks in accordance with the load spectrum presented in Fig. 2. Striation spacing values in the series of thick striations in Fig. 11a are $3.3 \mu \mathrm{m}$ while in Fig. $11 \mathrm{~b}$ they are invariable and are approximately equal to $2,8 \mu \mathrm{m}$.

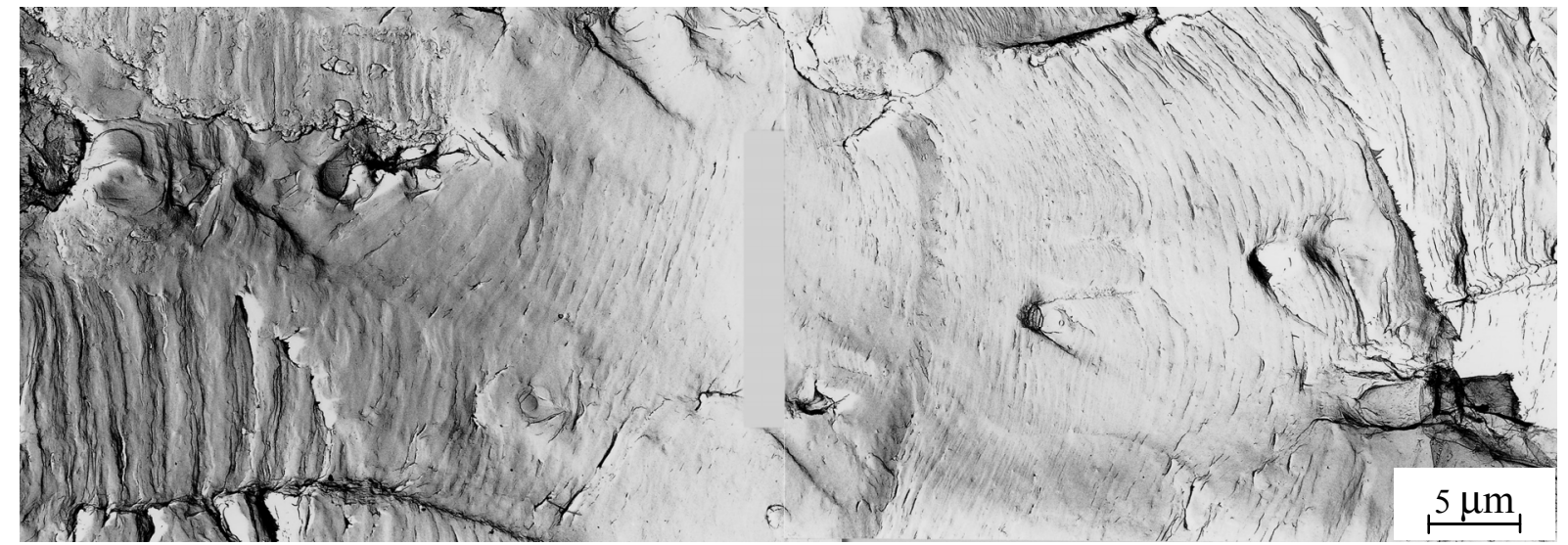

Fig.10 A pattern of fatigue striations on the fracture surface of the 2024-T3 alloy
L-T specimen observed under the TEM within the part of stress spectrum
in the range of the lengths of $8-11 \mathrm{~mm}$ from the precrack front (explained above)

The presented images of thick and thin fatigue striations correspond well with the distribution of measuring points in the diagrams of crack growth rates in L-T specimens presented in Fig. 8a. In the range of the crack lengths of up to $4.5 \mathrm{~mm}$, at the beginning, there occurred a higher crack growth rate which lasted for a short period of time. Subsequently the rate dropped or it settled at an invariable level. Next, the crack growth rate was increasing quite rapidly until the specimen was destroyed.
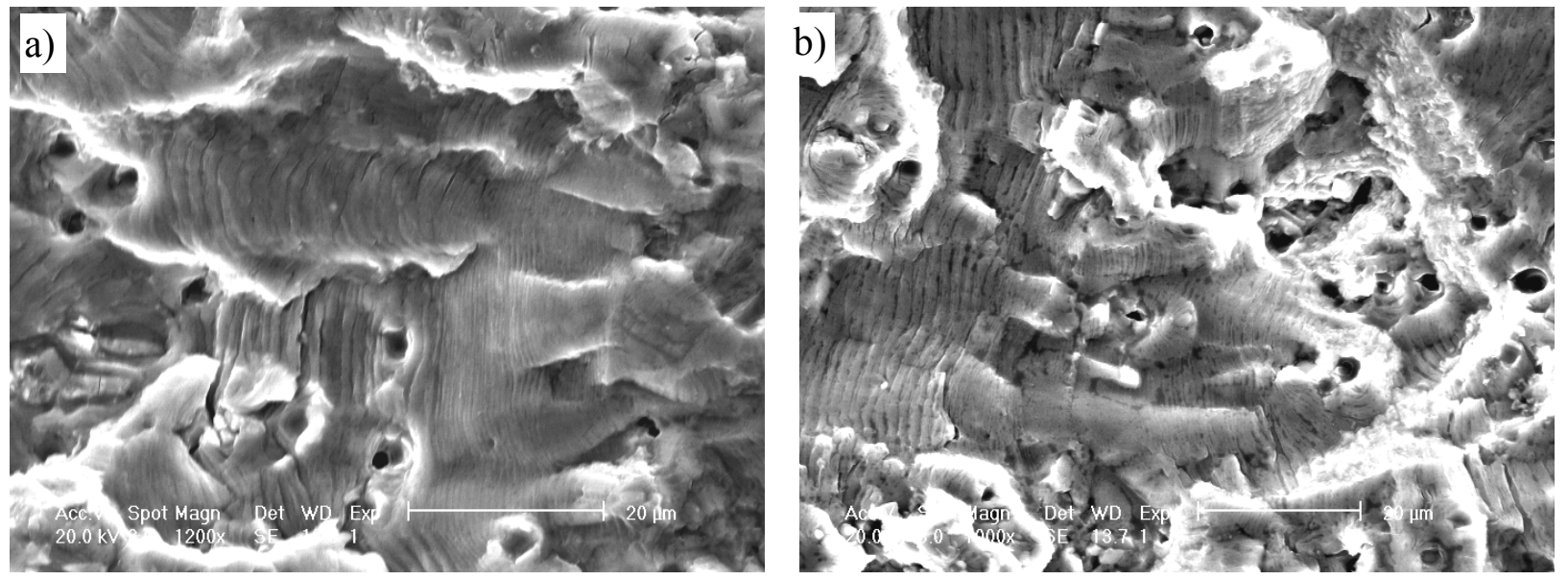

Fig.11. The examples of fracture surfaces in the 2024-T3 aluminium alloy observed under the SEM from the distance of $1.5 \mathrm{~mm}$ (a) and $3.5 \mathrm{~mm} \mathrm{(b)} \mathrm{from} \mathrm{the} \mathrm{precrack} \mathrm{front} \mathrm{(explained} \mathrm{above)}$

It is curious that the consistency of crack growth rates occurs both in a macroscopic and microscopic scale. The former concerns the spacing between fatigue lines and the latter concerns the fatigue striation spacing, which differ in terms of dimensions by 2-3 orders of magnitude. The consistency, or rather macroscopic analogy, is repeated in very narrow bands with overload striations which correspond to 10, 25 or alternatively 20 load cycles (load levels 1-2-3). The analysis of fracture surfaces under the TEM and partially under the SEM confirmed the occurrence of temporary crack growth delay and crack closure caused by overload cycles in the stress spectrum. There is a need to underscore the importance of microfractographic analysis carried out with the use of electron microscopes (the TEM microscope in particular). The appropriate 
preparation of replicas of fractures is crucial for the research carried out with the use of the TEM. Making replicas is, in general, a very laborious task. Working out the proper technique of making replicas led to obtaining clear and legible images as in Figures 9 and 10. Whereas the analysis by means of the SEM is characterized by great simplicity since the crack surface can be observed directly under the microscope, which is a great convenience. On the other hand, there is usually a decrease in the quality and the precision of the images obtained by the SEM. Comparing the images in Fig. 9, 10 and 11, it is easy to notice the difference in quality between the images obtained by means of the TEM and the SEM. The patterns of striations noticeable in the microconfiguration of crack surfaces in the images obtained by the TEM in Fig. 9a and 10 made it possible to determine the changes in crack growth rates in the spectrum, that is, in a microscopic scale. The changes are illustrated in the diagram in Fig. 12. Similarly as for the OVL program, two scales were used, namely the upper scale relating to the striation spacing and the lower scale relating to the point at which the specimen for the TEM analysis was taken. Crack growth rates determined from the striation spacing data and corresponding to particular load levels of the LHL spectrum are marked in the diagram. The patterns of striations are characteristic of the spectra in the range of crack lengths of $2-11 \mathrm{~mm}$. The high initial crack growth rate manifested in thick fatigue striations decreases significantly from $10^{-3} \mathrm{~mm} /$ cycle to $10^{-4} \mathrm{~mm} /$ cycle, subsequently, it decreases rapidly to $10^{-6} \mathrm{~mm} /$ cycle. The decrease manifests itself in single measuring points in the lower part of the diagram in Fig. 12.

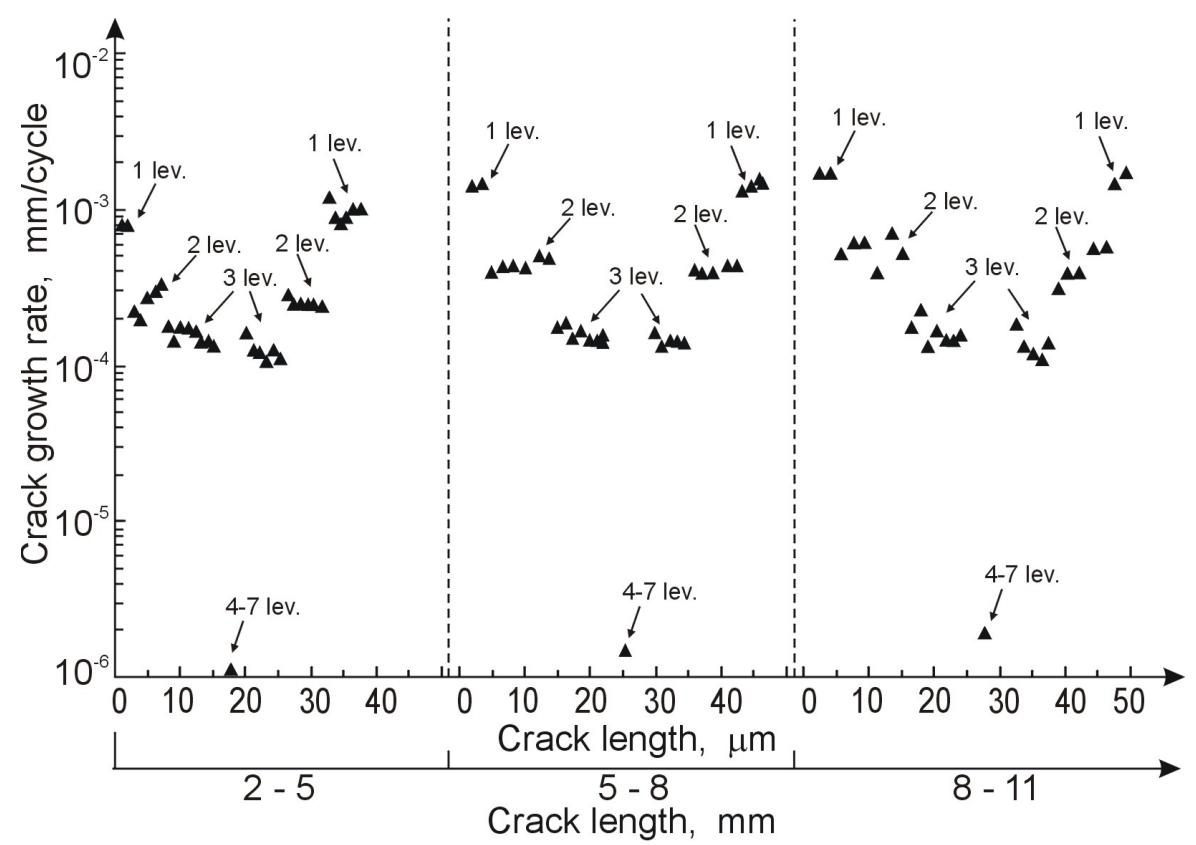

Fig.12. Courses of local crack growth rate against crack length; see text for explanation

The decrease in the crack growth rate in specimens encompasses three orders of magnitude. Then, there occurs a comparably rapid and gradual increase in the crack growth rate also by three orders of magnitude. The phenomenon of the rapid decrease and increase in the crack growth rate occurs in the middle part of each crack length range in the diagram in Fig. 12. It manifests itself in the narrow bands with either no striations or the traces of striations, which can be observed in the central parts of the images in Fig. 9 and 10. The microfractographic analysis proved that short loading cycle sequences (as regards the number of cycles) and successive loading blocks which occur at relatively short intervals reduce the possibility of complete reconstruction of the loading spectrum on the basis of the microfractographic analysis in damaged components. 


\subsection{Test results for FBF load program}

The FBF load program (Fig. 4) has a common derivation with the LHL-100 block program but differs from this latter the ordering and the number of cycles in the particular blocks. The FAF sequence includes only one spike overload-underload of highest stress ratio $\mathrm{S}_{\mathrm{ULmin}} / \mathrm{S}_{\mathrm{OVmax}}=-0.15$. The interaction of this loading on the crack growth behaviour one can learn considering the experimental results performed in the Fig. 13 and 16 as well as the TEM micrograph in Fig. 14. To perform the load test results the courses of crack growth rates against visually measured surface crack length for two LT specimens (Fig. 13a) and two TL specimens (Fig. 13b) were compared with the result derived by the CA test. It might be expected that the growth rates under FBF loading were bellow the CA data.
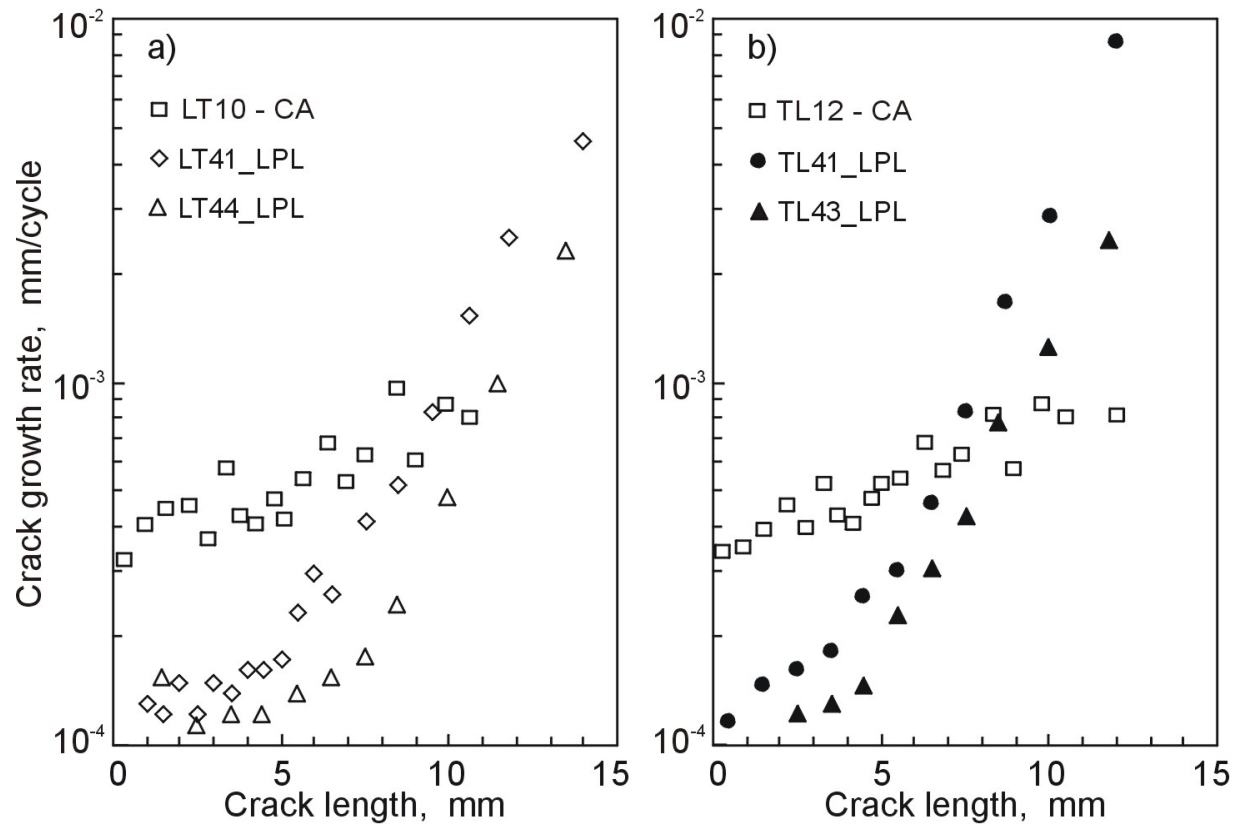

Fig. 13. Comparison of crack growth rate under FBF cycle sequence and under $C A$ against measured crack length for specimens taken in directions parallel (a) and transverse (b) due to rolling

However, more details of the load influence on the crack growth behaviour derived the TEM micrographs. Exemplary TEM micrograph attributed to the FBF loading presents Fig. 14. The changes of the local crack growth rate within one sequence was estimated cycle by cycle on the basis of the TEM measurements taken from different spots on the fracture surface.

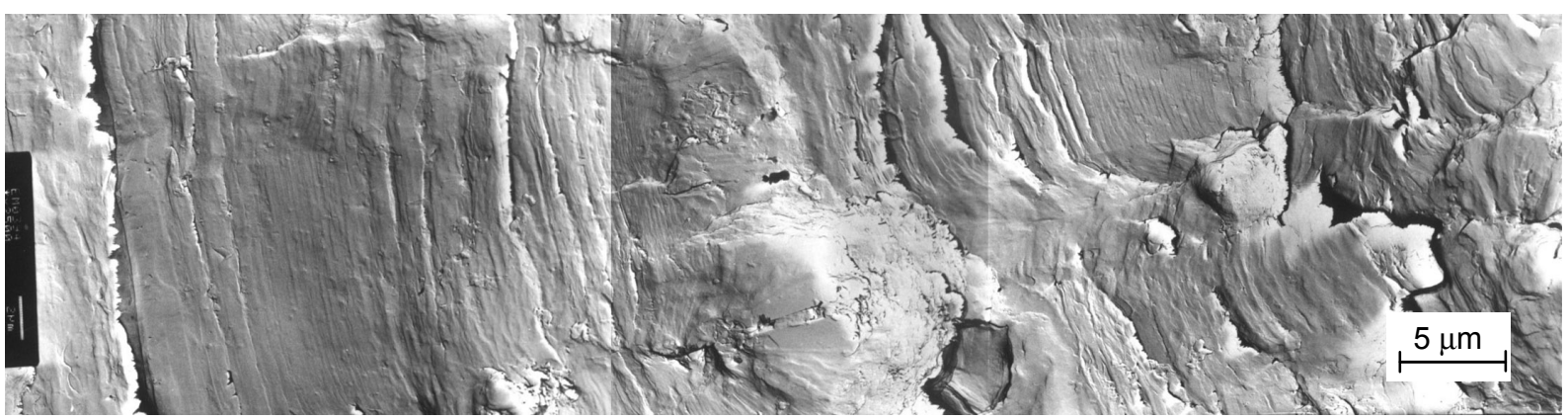

Fig. 14. TEM micrograph with fatigue striations on the fracture surface attributed to FBF load program

Also the microfractographic analysis by means of the SEM microscope provided the images of the fracture surfaces of specimens subjected to FBF loads. The characteristic patterns of fatigue striations on the fracture surface of the 2024-T3 alloy L-T specimen can be observed in the image 
in Fig. 15. It shows the groups of repeating striations of different widths. The image illustrates fatigue striations corresponding to a complete sequence of stress blocks in the FAF program. In the middle of the image, one can identify the thickest striations. Each of them corresponds to the cycle with the highest stress value in the Flight-B block connected with load level 1.

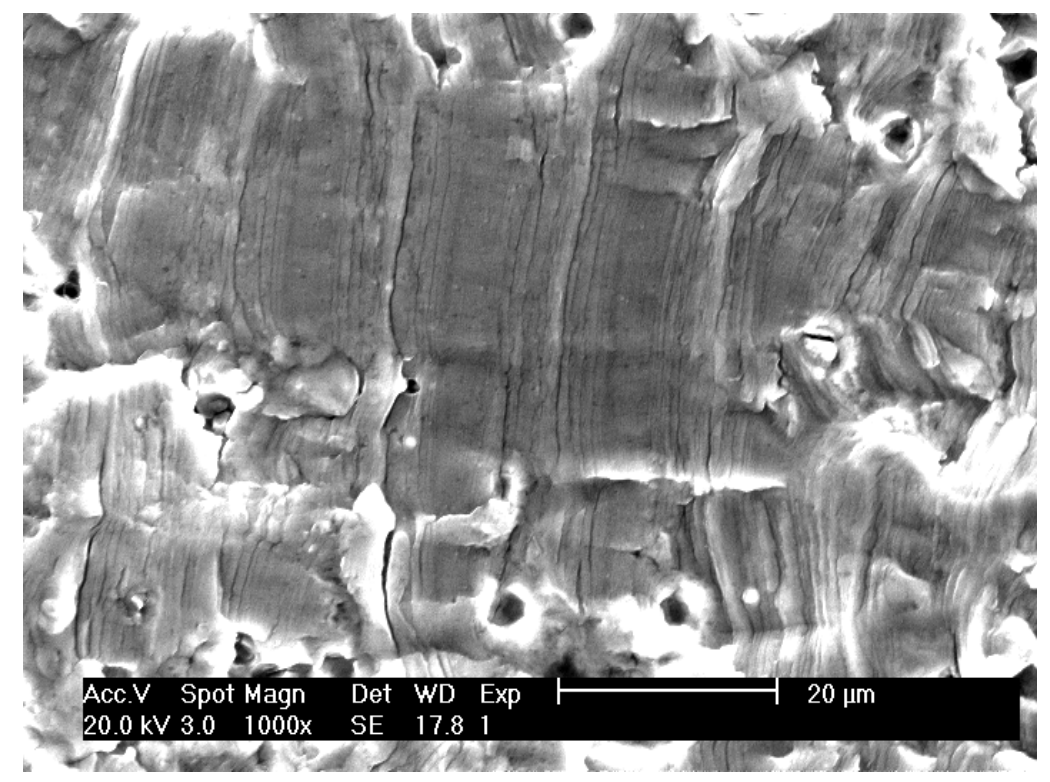

Fig. 15 The patterns of fatigue striations on the fracture surface of the 2024-T3 alloy $L-T$ specimen under the FAF stress spectrum.

The cycle with the highest stress value in the spectrum (level 1) caused a rapid increase in the crack growth rate and the crack increment that is manifested in the form of a wide flat band between the crack and the next three striations formed as a result of the operation of three cycles of level 2 in the Flight-B block. The set of striations of the same width, which can be observed in the central part of the image, corresponds to stress level 4 (both for the Flight-A block and the FlightB block). The plastic zone created by the highest cycle encompasses 220 striations. That number of striations corresponds to the nine fold repetition of the Flight-A block and 23 striations formed during the operation of cycles of levels 4-7 in the Flight-B block. It denotes that the crack growth rate was very low during 220 cycles in the spectrum. Then, each high-density series of striations which is noticeable in the image in Fig. 15 and on the macrofracture as a fatigue line consists of 10 striations formed during the operation of 10 cycles of levels 3-2-1-2-3 and 10 striations corresponding to level 4 in a complete FAF program. The diagrams of crack growth rates (in a microscopic scale) assessed on the basis of the fatigue striation spacing on the fracture surfaces of specimens (the upper crack length axis in the diagram) are presented in Figure 16. The segments of fracture surfaces taken at different distances from the mechanical notch (the lower crack length axis in the diagram) were compared. Fatigue striations corresponding to the four highest stress levels in the FBF load spectrum were identified during the microfractographic examination. The points corresponding to the crack growth rates determined from the striation spacing and correlated with the highest load levels in the FBF program were marked in the abovementioned diagram. The data points shown in Fig. 16 indicate that the highest spike overload and underload cycle of the first stress level plays an important role in the sequence producing a widest striation. On the other side underloading reduces the effect of crack retardation. In the case of FBF loading the crack propagation period covers only 22 cycles per 240 cycles that belong to the whole sequence. In the micro scale crack growth rate attributed to one spike overload-underload cycle is almost three times higher than this one resulted from the action of ten immediately following spike overload-underload cycles in the LHL-100 program. 


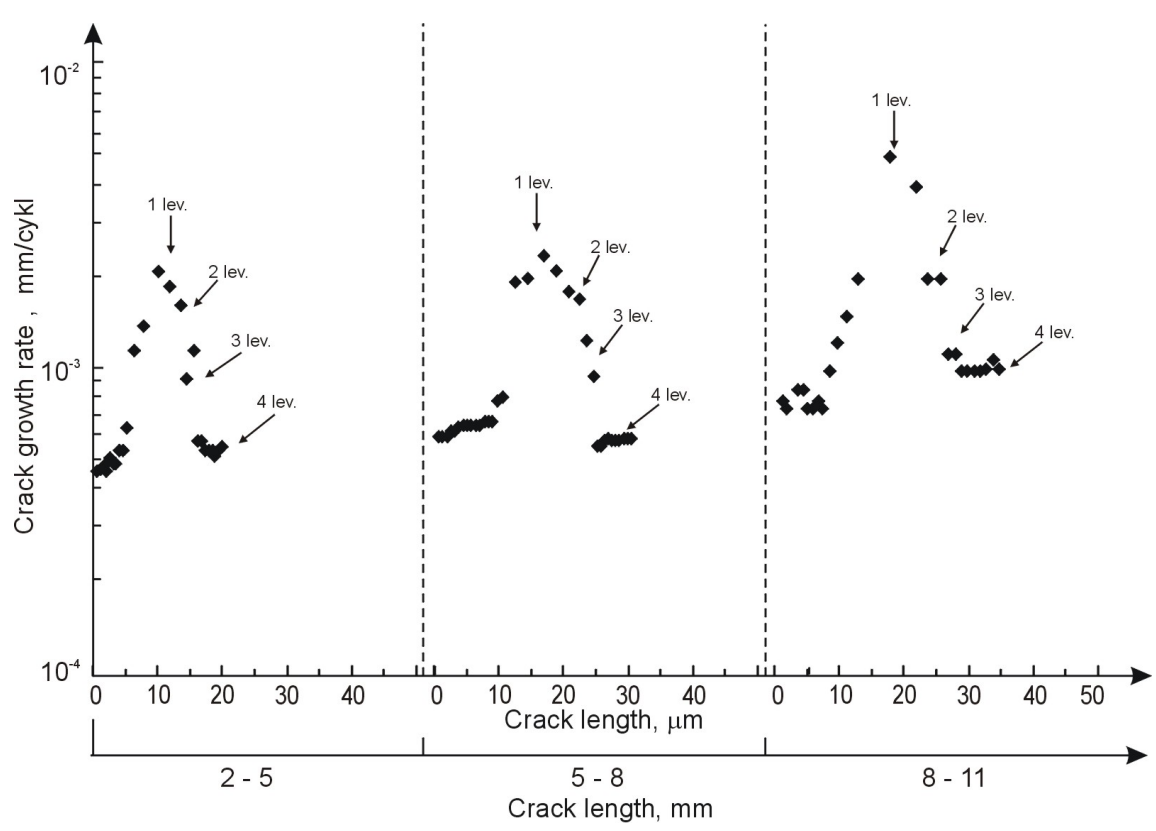

Fig. 16. Courses of local crack growth rate against crack length; see text for explanation

Finally, the lifetimes of the specimens tested under the FBF loading are lower than those ones under the LHL-100 block program. In the case of a complex VA load sequences with a certain number of immediately following spike overloads-underloads the reconstruction of the load-time history on the basis of microfracture analysis is limited. The TEM observations allow identifying only part striations attributed to the particular cycles in the load sequence. This limited reconstruction results also from short return period load programs considered here. Our research developed in this field indicate that in the case of simple load programs with block of spike overloads-underloads with longer return periods the correlation between the fatigue striations and the relevant load cycles is very good in whole range of crack length.

It was established thanks to the microfracture analysis relation (1a) and (1b) which capture the relationship among the crack growth rate on the surface and inside the element calculated from the mutual distance between striations observed on the fracture. The relations (1) include the whole range of the length of cracks, from small to long cracks. For small cracks, in $3 \mathrm{~mm}$ thickness of the sheet metal of the alloy 2024-T3 they include the range to $3 \mathrm{~mm}$ of the length, the value of constant A changes in the formula (1a) within the range $0.7 \div 0.45$.

$$
\begin{gathered}
\delta=\frac{d a}{d N}=A \cdot \frac{\Delta K^{2}}{R_{e} \cdot E} \\
\delta=\frac{d a}{d N}=B \cdot\left(\frac{\Delta K}{E}\right)^{c}
\end{gathered}
$$

It should be mentioned that the value $\mathrm{A}=0.7$ relates to the smaller lengths of cracks but the value $A=0.45$ - bigger lengths. The constant $A$ in the formula (1a) connects to cyclic hardening (softening) of elastic-plastic material.

For long cracks developing in the aluminium alloys, in the central range of the curve of cracking, the equation (1b) passed by Bates and Clark [21] is important. In the original formula the constant $\mathrm{B}$ amounts to about 6 and $\mathrm{c}=2$. It should be marked that the values of constants were given for aluminium alloy sheet. In accordance with our investigations made for Alclad 2024-T3 aluminium alloy sheet values of the constants are as follows: $\mathrm{c}=2$ and $\mathrm{B}=11.5$. 

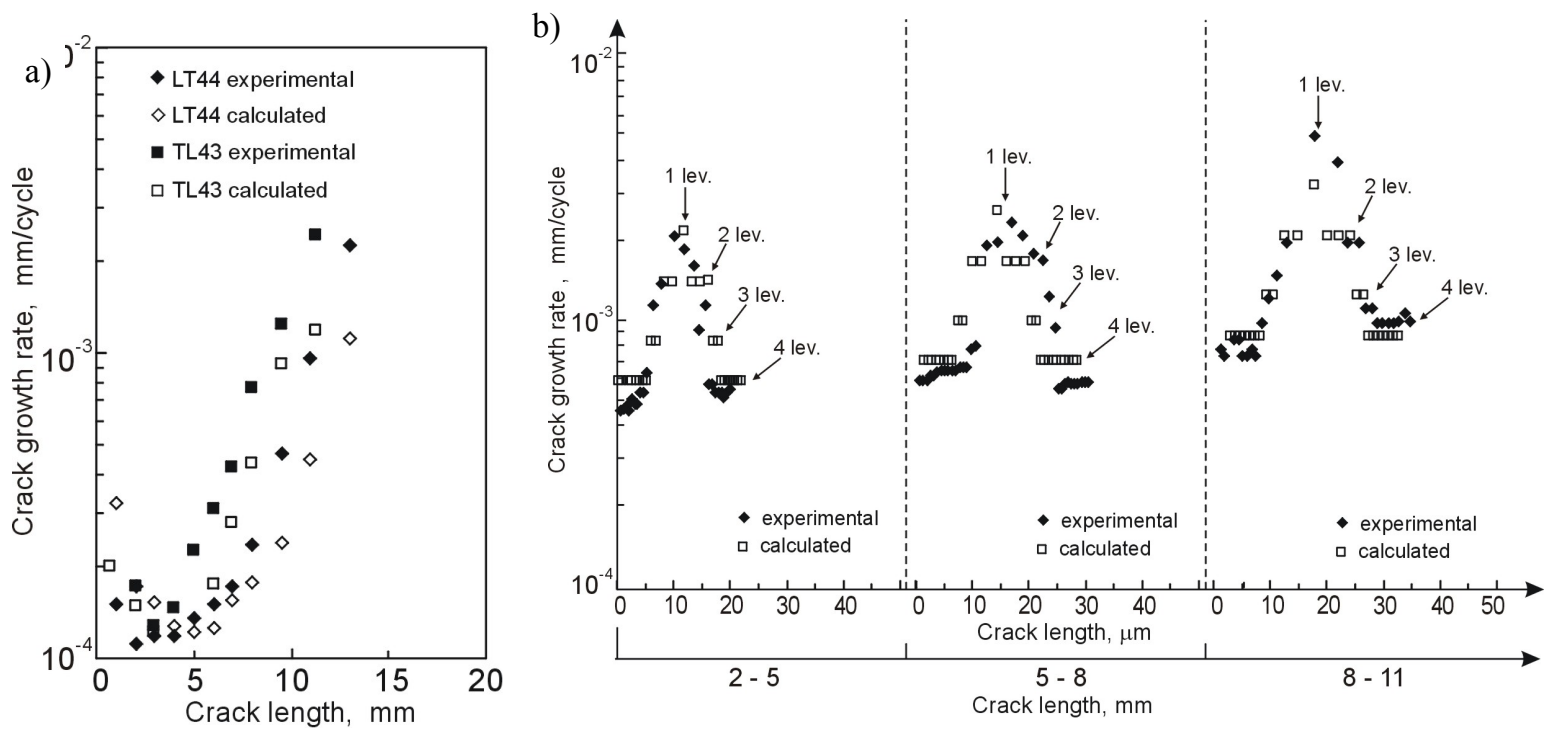

\section{Rys. 17. Courses of crack growth rates for the $L T$ and $T L$ specimens in a macroscopic scale (a) and in a microscopic scale (b) against crack length attributed to FBF load program; see text for explanation.}

The results of the comparison are presented in the diagrams in Fig 17. Open symbols indicate values obtained by calculations, while filled-in-black symbols refer to experimentally determined crack rates. In Fig. 17a it is seen well correlation between experimentally determined crack growth rate in the range of the small cracks on the basis of fatigue striations spacing (Fig. 17b) and the growth rate calculated from equations (1a). Similarly, this comparison was made also for long cracks entering in Fig. 17a the values of crack rate calculated from equation (1b). Relationships (1a) and (1b) have practical application. They allow for estimating the length of crack depth for a given surface crack length.

\section{SUMMARY}

The study for 2024-T3 aluminium alloy sheet was undertaken in order to learn about the influence of variable amplitude loading with repeated spike overload-underload cycles on the fatigue crack growth behaviour. Three load sequences were considered here, namely simple OVL load program, the FBF (flight-by-flight) cycles sequence and LHL-100 block program that differed from each other the ordering and the number of various magnitude overloads or spike overload and underload cycles. The results indicate that the first overload-underload cycle in the sequence of either the FBF or the LHL-100 loads plays very important role. One high spike overload and underload cycle in the FBF sequence more reduces the effect of crack retardation than the block with ten immediately following spike overloads-underloads in the LHL-100 program. In result the lifetimes of the specimens tested under the FBF loading are lower than those ones under the LHL-100 block program. The research proves the feasibility of load time history reconstruction of a failed component operated under simple loading like as OVL load program. The research proves as well that a short return periods occurred in the variable amplitude loadings with a certain number of immediately following spike overload-underload cycles introduce the limitation for doing the reconstruction of the load-time history on the basis of microfracture analysis. 


\section{REFERENCES}

[1] Kocańda, S. (1990). Metal Fatigue. Part III in Experimental Methods in Mechanics of Solids. Amsterdam-Oxford-New York: Elsevier.

[2] Kocańda, D., Kocańda, S., \& Torzewski, J. (2002). Fatigue crack growth rate in 2024-T3 aluminium alloy. In: Proceedings of the $19^{\text {th }}$ Symposium on Fatigue and Fracture Mechanics, April 2002, (195-202). Bydgoszcz: ATR.

[3] Wanhill, R. J. H. (2002). Flight simulation fatigue crack growth guidelines. In: Proceedings of the $8^{\text {th }}$ International Fatigue Congress, 2-7 June 2002, 1(5), 573-584. Stockholm, Sweden.

[4] Spence, S. H., Williams, N. M., Stonham, A. J., Bache, M. R., Ward, A. R., Evans, W. J., Hay, D., Urbani, C., Crawford, B. R., Loader, C., \& Clark, G. (2002). Fatigue in the presence of corrosion pitting in an aerospace aluminium alloy. In: Proceedings of the $8^{\text {th }}$ International Fatigue Congress, 2-7 June 2002, 1(5), 701-708. Stockholm, Sweden.

[5] Katoh, Y., Nakayama, H., \& Tanaka, T. (2002). Fatigue crack growth behaviour of aluminium alloy under three-step varying load. In: Proceedings of the $8^{\text {th }}$ International Fatigue Congress, 2-7 June 2002, 2(5), 1459-1466. Stockholm, Sweden.

[6] Sunder, R. (2002). An explanation for the residual stress effect in metal fatigue. In: Proceedings of the $8^{\text {th }}$ International Fatigue Congress, 2-7 June 2002, 5(5), 3339-3350. Stockholm, Sweden.

[7] Gangloff, R. P. (2002). Environment sensitive fatigue crack tip process and propagation in aerospace aluminium alloys. In: Proceedings of the $8^{\text {th }}$ International Fatigue Congress, 2-7 June 2002,Vol. 5(5), 3401-3430. Stockholm, Sweden.

[8] Forth, S. C., Keat, W. D., \& Fawrow, L. H. (2002). Experimental and computational investigation of three-dimensional mixed-mode fatigue. Fatigue and Fracture of Engineering Materials and Structures, 25(1), 3-15.

[9] Schijve, J. (2002). Fatigue of structures and materials in the $20^{\text {th }}$ century and the state of the art. In: Proceedings of the $14^{\text {th }}$ Bienniel Conference on Fracture-ECF 14, 2002, Vol. III/III, 211-262.

[10] Schijve, J. (2001). Fatigue of structures and materials, Dordrecht, Boston, London: Kluver Academic Publishers.

[11] Zhang, X. P., Wang, C. H., Ye, L., \& Mai, W. ( 2002). In situ investigation of small fatigue crack growth in poly-crystal and single-crystal aluminium alloys. Fatigue and Fracture of Engineering Materials and Structures, 25(2), 141-150.

[12] Kermanidis, A. T., \& Pantelakis, S. G. (2001). Fatigue crack growth analysis of 2024-T3 aluminium specimens under aircraft service spectra. Fatigue and Fracture of Engineering Materials and Structures, 24, 699-710.

[13] Ranganathan, N. (2002). Certain aspects of variable amplitude fatigue. In: Proceedings of the $8^{\text {th }}$ International Fatigue Congress, 2-7 June, 2002, 1(5), 613-621. Stockholm, Sweden.

[14] Brockenbrough, J. R., Bucci, R. J., Kulak, M., Zonker, H. R., Bray, G. H., Heinimann, M. B., \& Newman, J.C. (2003). Crack growth prediction methods for spectrum loading to support fatigue and durability damage tolerance evaluation. In: Proceedings of the $22^{\text {nd }}$ Symposium of International Committee on Aeronautical Fatigue - Fatigue of Aeronautical Structures as an Engineering Challenge, 5-9 May 2003, Vol. 1, pp. 14. Lucerne, Switzerland.

[15] Goncalves, W., Pramono, A., \& Chaves, C. E. (2003). Embraer New Family of Jets-Meeting the Current Fatigue and Damage Tolerance Requirements. In: Proceedings of the $22^{\text {nd }}$ Symposium of International Committee on Aeronautical Fatigue - Fatigue of Aeronautical Structures as an Engineering Challenge, 5-9 May, 2003, Vol 1, pp. 21. Lucerne, Switzerland.

[16] Lazzeri, L., \& Ratti, G. (2002). Fatigue crack propagation in thin sheets under typical helicopter spectra. In: Proceedings of the $8^{\text {th }}$ International Fatigue Congress, 2-7 June 2002, 1(5), 585-592. Stockholm, Sweden. 
[17] Iyyer, N. S., Kwon, Y. S., \& Phan, N. (2003). P-3C crack growth life predictions under spectrum loading. In: Proceedings of the $22^{\text {nd }}$ Symposium of International Committee on Aeronautical Fatigue - Fatigue of Aeronautical Structures as an Engineering Challenge, 5-9 May 2003, Vol. 2, pp. 18. Lucerne, Switzerland.

[18] Skorupa, M. (1996). Empirical trends and prediction models for fatigue crack growth under variable amplitude loading. Petten, Netherlands: Energy Research Foundation. (ECN-R-96007)

[19] Ivanova, V., \& Shaniavsky, A. (1998). Quantitative fractography. Metallurgy Press.

[20] Kocanda, D., Kocanda, S., \& Torzewski, J. (2004). Reconstruction of fatigue crack growth rate for 2024-T3 aluminium alloy sheet on the basis of fractographic analysis. The Archive of Mechanical Engineering, 51(3), 361-376.

[21] Hertzberg, R. (1983). Deformation and fracture mechanics of engineering materials, John Wiley $\&$ Sons Inc., $2^{\text {nd }}$ revised edition.

[22] Karasiewicz, T., Bogdanowicz, Z., \& Polanski, J. (2007). The influence of amplitude and load rate on the amount of energy dissipation for aluminium alloy subjected to cyclic torsion. Bulletin of Military University of Technology WAT, 56(4). Warsaw, Poland.

[23] Szymczyk, E., Jachimowicz, J., \& Bogdanowicz, Z. (2007). Investigations of fatigue crack initiation in rivet-joints. Transactions of the Kielce University of Technology. Mechanics, 4. 125-126. (in Polish). Warsaw, Poland.

[24] Bogdanowicz, Z. (2008). Elaboration of the method of aeronautical skin joints lifetime determination taking into account materials and technological features. Sc. Project, (in Polish). Warsaw, Poland: Military University of Technology. 